\title{
FISIBILITAS PILKADA SERENTAK TAHAP II KOTA PEKANBARU PASCA PERMENDAGRI NO 18 TAHUN 2015
}

\author{
Alexsander Yandra \\ Universitas lancang Kuning \\ Email: alexsy@unilak.ac.id
}

\begin{abstract}
Feasibility Phase II simultaneous elections in the city of Pekanbaru post-Regulation No. 18 in 2015 affect the population administration and the right to vote of citizens, could be implicated cause some residents do not get a voter card. The Regulation boundary change Pekanbaru and Kampar namely RW 15,16 and 18 villages of three districts of the hill highway intersection that previously pekanbaru region into an area of Kampar. Thus, the Election Commission Pekanbaru as election organizers make an effort assessment mapping and data collection forms of suffrage of citizens in the disputed area in order to participate in the elections. Using descriptive qualitative method with theoretical concept of political interest in the election and Elections To Local as well as data analysis through interpretation of ethics and EMIC is further elaborated in the study of electoral governance in accordance with the discussion of the study. The results of this study demonstrate the efforts made by the Election Commission of Pekanbaru in data collection and mapping of suffrage of citizens in the border area of Pekanbaru and Kampar walk is not optimal for a long period of time but has shown improvement on the sustainability of suffrage in the interests of the election. Furthermore, citizens residence status does not match the expectations of citizens citizens in the response resulted in three $R W$ at the intersection of three villages regarding the status of permanent voters list (DPT) on the elections, simultaneous phase II have a tendency not to vote.
\end{abstract}

Keywords: suffrage, interests and local elections.

Abstrak

Fisibilitas Pilkada serentak tahap II di Kota Pekanbaru pasca permendagri no 18 tahun 2015 berpengaruh terhadap administrasi kependudukan dan hak pilih warga, bisa berimplikasi menimbulkan sebagian warga tidak mendapat kartu pemilih. Permendagri tersebut merubah tapal batas Pekanbaru dan Kampar yaitu RW 15,16 dan 18 kelurahan simpang tiga kecamatan bukit raya yang sebelumnya wilayah pekanbaru menjadi wilayah kampar. Maka, KPUD Kota Pekanbaru sebagai penyelenggara pilkada melakukan upaya asesmen bentuk pemetaan dan pendataan hak pilih warga di daerah yang bersengketa tersebut agar bisa berpartisipasi dalam pilkada. Menggunakan metode kualitatif deskriptif dengan konsep teori kepentingan politik dalam pilkada dan Pemilihan Kepada Daerah serta analisis data melalui interpretasi etik dan emik kemudian dielaborasi dalam kajian tata laksana kepemiluan sesuai dengan pembahasan yang diteliti. Hasil penelitian ini menunjukkan upaya yang dilakukan oleh KPUD Kota Pekanbaru dalam pendataan dan pemetaan hak pilih warga di daerah perbatasan Pekanbaru dan Kampar berjalan belum optimal untuk jangka waktu yang panjang namun sudah menunjukan perbaikan terhadap keberlanjutan hak pilih sementara untuk kepentingan pilkada. Selanjutnya status kependudukan warga tidak sesuai dengan harapan warga berakibat respon warga masyarakat di tiga $R W$ di kelurahan simpang tiga terkait status daftar pemilih tetap (DPT) pada pilkada serentak tahap II memiliki kecendrungan untuk tidak memilih.

Kata Kunci: Hak pilih, Kepentingan dan Pilkada.

\section{PENDAHULUAN}

Fisibilitas Pilkada langsung dan serentak masih sarat akan masalah. Dari beberapa permasalahan terlihat adanya hal-hal yang menonjol diantaranya, banyak pemilih yang tidak terdaftar, hak pilih warga terabaikan, maraknya politik uang (money politics) dalam pencalonan dan pemungutan suara, tidak 
netralnya PNS dan sebagian aparat pelaksana, calon incumbent menyalahgunakan jabatan, tidak terjaringnya calon perseorangan (independent), jeleknya penyelesaian sengketa suara, tidak bonafiednya kepala daerah terpilih, isu kampenye yang menyuarakan kepentingan identitas etnis, serta masalah tapal batas daerah yang menimbulkan persaingan yang sangat kompetitif karena terkait sumber suara pemilih sehingga sarat akan konflik, serta pecahnya kongsi kepala daerah dan wakil kepala daerah.

Terkait dengan itu pilkada serentak tahap II tahun 2017 Provinsi Riau dilaksanakan di Kota Pekanbaru dan Kabupaten Kampar juga sarat masalah, khususnya daerah perbatasan Pekanbaru dan Kampar terjadi sengketa dan perebutan tiga Rukun Warga (RW) yaitu RW 15, 16, dan 18 Kelurahan Simpang Tiga, Kecamatan Bukit Raya. Ketiga RW ini sebelumnya dalam Peraturan Pemerintah (PP) Republik Indonesia Nomor 19 tahun 1987 tentang perubahan batas wilayah kotamadya daerah Pekanbaru dan Kampar, yang menyebutkan daerah tersebut menjadi bagian kependudukan Pemko Pekanbaru. Akan tetapi sejak keluarnya Peraturan Menteri Dalam Negeri (Permendagri) No 18 tahun 2015 tentang tapal batas Pekanbaru dan Kampar, tiga RW ini menjadi wilayah daerah dan kependudukan Kabupaten Kampar.

Perubahan terhadap tapal batas pekanbaru-kampar berdampak terhadap administrasi kependudukan dan hak pilih warga di tiga RW tersebut, apakah masih tetap sebagai pemilih di pilkada Kota Pekanbaru atau justru menjadi pemilih dalam pilkada Kabupaten Kampar yang akan dilaksanakan pada 15 Februari 2017 nanti. Walaupun sebelumnya warga tiga RW tercatat dalam daftar pemilih tetap di Pekanbaru tentunya setelah terjadi pergeseran status tiga RW menjadi Kampar, maka daftar pemilih akan mengikuti perubahan wilayah, artinya daftar pemilihnya menjadi daftar pemilih untuk pilkada Kampar. Hal ini menjadi polemik baik bagi masyarakat tempatan (RW 15,16 dan 18), kandidat yang ikut berkompetisi dan penyelenggara sendiri. Kekwatiran akan terjadi, jika perebutan terhadap hak pilih warga berujung kepada konflik pilkada serentak tahap II di Provinsi Riau.

Hal inilah yang menjadi tugas KPUD Riau untuk mengkonsolidasikan kepada KPUD Pekanbaru dan Kampar untuk mampu merumuskan suatu solusi serta kesepakatan bersama terhadap kepastian hak pilih warga di tiga RW yang disengketakan oleh kedua pemerintah daerah yang akan melaksanakan Pilkada. KPUD Riau harus mampu menjadi mediator dan katalisator terhadap polemik yang terjadi diantara penyelenggara dalam penetapan daftar pemilih tetap di tiga RW. Dari permasalahan tersebut di atas, peneliti merumuskan resolusi politik yaitu upaya penyelamatan hak pilih warga oleh KPUD Riau di daerah perbatasan Pekanbaru dan Kampar yang pada dasarnya akan melaksanakan pilkada serentak tahap II di Provinsi Riau. Berharap dengan adanya resolusi politik, usaha dan upaya yang dilakukan KPUD Riau, dapat mendinamisasi permasalahan yang terjadi serta tidak menggangu stabilitas penyelenggara pilkada dikemudian hari. Penelitian ini mengkaji secara komprehensif upaya yang dilakukan oleh KPUD Riau dalam penyelamatan hak pilih warga di RW 15, 16 dan 18 Kelurahan Simpang Tiga Kecamatan Bukit Raya Kota Pekanbaru menyonsong pilkada 2017. Untuk itu, peneliti mengajukan kajian literatur sehingga dapat memaparkan secara mendalam resolusi politik dalam upaya penyelamatan hak pilih warga RW 15, 16 dan 18 Kelurahan Simpang Tiga.

Kepentingan Politik Dalam Pilkada

Webster mendefenisikan kepentingan adalah perasaan orang mengenai apa yang sesungguhnya ia inginkan dan rasakan, dimana perasaan itu cenderung bersifat sentral dalam pikiran dan tindakan orang yang membentuk inti dari banyak sikap, tujuan dan niat (Yandra dalam Jurnal Avicenna volume 4 nomor 1 tahun 2014). Menurut Firdaus Putra Aditama kepentingan di kelompokan menjadi dua yaitu kepentingan individu dan kepentingan sosial. Kepentingan individu" sebagai kepentingan yang dimiliki oleh setiap individu atau manusia dalam konteks kehidupan bermasyarakat. Seperti kepentingan ekonomi, politik, sosial-budaya dan ideologi atau sistem kepercayaan-keyakinan. kepentingan individu paralel 
dengan logika kebutuhan yang dicetuskan oleh Maslow. Ia memetakan bahwa setiap individu minimalnya mempunyai lima jenjang kebutuhan pokok (hierarchi of needs). Pertama adalah kebutuhan sandang, pangan, papan kedua adalah kebutuhan rasa keamanan; ketiga adalah kebutuhan untuk bersosialisasi; keempat adalah kebutuhan untuk mendapatkan pengakuan sosial; dan kelima kebutuhan untuk beraktualisasi diri. Dengan definisi "kepentingan individu" per definisi kebutuhan individu cukup komprehensif untuk membaca aktivitas individu dalam kehidupan (Yandra dalam Jurnal Avicenna volume 4 nomor 1 tahun 2014).Sedangkan "kepentingan sosial" sebagai kepentingan yang dimiliki oleh masyarakat atau keinginan bersama antar anggota masyarakat untuk mewujudkan suatu tujuan bersama. Dalam kepentingan ini tersirat tentang konsensus bersama, sebuah kesepakatan tentang hal-hal yang dibutuhkan oleh masyarakat untuk berlangsungnya atau lestarinya masyarakat, misal kepentingan untuk menjaga nilai, norma yang ada di masyarakat. Kepentingan untuk menjaga nilai, norma berangkat dari asumsi bahwa dengan perangkat nilai, norma itulah masyarakat mampu bertahan dan eksis dalam kehidupannya.

Pemilihan Kepala Daerah (Pilkada)

Menurut Joko J. Prihatmoko Pemilu Kada langsung melibatkan, mendorong dan membuka akses partisipasi seluruh warga yang memenuhi syarat sebagai pemilih dan terbuka kemungkinan sebagai calon, serta pengawal proses pelaksanaan. Sebaliknya, Pemilu Kada tidak langsung adalah Pemilu Kada yang tidak membuka akses bagi warga secara langsung baik sebagai pemilih maupun pengawal proses pelaksanaan (Prihatmoko, 2005:71). Joko J. Prihatmoko mendefenisikan Pemilu Kada dari sudut partisipasi yaitu sejauh mana peluang masyarakat untuk berpartisipasi dalam Pemilu Kada, baik sebagai peserta, pemilih, maupun pengawas dalam pelaksananannya,Menurut Sarundajang Pilkada langsung sebagai suatu wadah untuk masyarakat memilih calon tertentu, sedangkan Pemilu Kada tidak langsung pemilihnya adalah anggota suatu badan pemilihan yang merupakan representatif dari masyarakat, anggota badan pemilihan tersebut dipilih secara langsung (Sarundajang 2005:18). Jika melihat Pilkada berdasarkan dari sisi pemilih, maka Pilkada tidak langsung pemilihnya adalah anggota suatu badan pemilihan, sedangkan Pemilu Kada langsung pemilihnya masyarakat yang telah memenuhi persyaratan untuk menjadi pemilih. Selain itu dalam pasal 1 PP Nomor 6 tahun 2005, Pemilu Kada langsung merupakan sarana pelaksanaan kedaulatan rakyat di wilayah Provinsi dan Kabupaten/ Kota berdasarkan Pancasila dan Undang-Undang Dasar Negara Republik Indonesia tahun 1945 untuk memilih Kepala Daerah dan Wakil Kepala Daerah. Defenisi Pilkada langsung yang dikemukakan J. Prihatmoko secara subtansi kurang relevan dengan kondisi saat ini. Alasannya, Pilkada masih belum membuka akses secara luas kepada masyarakat terutama kesempatan untuk menjadi calon Kepala Daerah, karena masyarakat tidak dapat mengajukan calon Kepala Daerah tanpa harus melalui Partai Politik (Parpol). Selain itu proses rekruitmen calon Kepala Daerah yang dilakukan Parpol cenderung membatasi kesempatan masyarakat dalam pengajuan calon kepala daerah. Untuk itu adanya peraturan yang membolehkan adanya calon independent untuk bisa mendaftar dalam pencalonan merupakan suatu usaha rekruitmen kepala daerah yang terbuka dan mengutamakan keinginan partisipasi dari masyarakat itu sendiri.

Sedangkan dalam penelitian ini Pilkada langsung dimaknai sebagai suatu proses demokrasi prosedural pada tingkat lokal (Provinsi dan Kabupaten/ Kota) yang mana masyarakat secara langsung ikut berpartisipasi dalam memilih Kepala Daerah dengan ikut mencoblos salah satu pasangan calon pada kertas suara. Dengan demikian defenisi Pilkada langsung dalam konteks pelaksananan Pilkada tahap II di Kota pekanbaru dan Kabupaten Kampar adalah suatu proses pemilihan kepala daerah dengan memanfaatkan sumber daya politik, yaitu partisipasi masyarakat lokal dalam memberikan hak suara pada kertas suara yang sangat mempengaruhi kepemimpinan politik kedepan di tingkat lokal. 


\section{METODE}

Penelitian ini menggunakan metode kualitatif dengan teknik penarikan informan melalui purposive sampling, karena mengutamakan kualitas data yang diperoleh melalui penyampaian informan terkait dengan masalah penelitian. Alasan pemilihan metode ini karena peneliti ingin memahami, mengkaji secara mendalam dan memaparkan terkait dengan penyalamatan hak pilih warga di RW 15, 16, dan 18 oleh KPUD agar tetap berpartisipasi dalam demokrasi aras lokal. Pendekatan dan desain yang digunakan dalam penelitian ini adalah studi kasus (study case), dengan tipe deskriptif dengan mencari pola hubungan antar gejala sosial dan menjelaskanya secara detil. John W. Creswell mengatakan bahwa studi kasus merupakan penelitian yang sering dilakukan penelitian politik dan pemerintahan (Creswell dalam Yandra,2013:98). Adapun unit analisis dalam penelitian ini adalah lembaga, karena untuk mengetahui terkait penetapan daftar pemilih tetap dalam rangka penyelamatan hak pilih warga adalah kewenangan lembaga penyelenggara pemilu dan lembaga pemerintah itu sendiri sebagai pencatatan administrasi kependudukan. Lembaga yang dijadikan unit analisis yaitu KPUD Provinsi Riau, KPUD Kota Pekanbaru, KPUD Kapubaten Kampar, Pemerintahan Kecamatan Bukit Raya dan Pemerintahan Kelurahan Simpang Tiga serta Lembaga Bawaslu sebagai pengawasan dalam pilkada nantinya.

Untuk mendapatkan data yang tepat, peneliti menggunakan beberapa teknik pengumpulan data, yakni : wawancara mendalam (indepth interview) dan dokumentasi yaitu pengumpulan arsip-arsip yang berhubungan dengan pengelolaan APBD Provinsi Riau Tahun 2015 (Yandra, 2015:9). Data diorganisasikan ke dalam kategori unit-unit, melakukan sintesa, menyusun ke dalam pola, dan membuat kesimpulan sehingga mudah dipahami oleh diri sendiri maupun orang lain (Sugiyono, 2005: 89). Seluruh data yang didapat akan dianalisis dengan menggunakan metode kualitatif melalui interpretasi. Proses ini mengklasifikasikan data ke dalam dua bagian, yaitu data etik (dari teori) dan data emik (dari temuan di lapangan). Selanjutnya proses reduksi hasil analisa data dapat menjadi terukur dan mampu dipertanggungjawabkan secara ilmiah bahkan menjadi temuan baru dalam mengembangkan teori.

\section{HASIL DAN PEMBAHASAN}

Fisibilitas Pilkada Kota Pekanbaru Tahun 2017 Pasca Permendagri No 18 tahun 2015 tentang tapal batas Pekanbaru dan Kampar.

a. Pemutakhiran Data Pemilih

Adanya Peraturan Pemerintah (PP) Republik Indonesia Nomor 19 Tahun 1987 tentang Perubahan Batas Wilayah Kotamadya Daerah Tingkat II Pekanbaru dan Kabupaten Daerah Tingkat II Kampar dan kemudian terbitnya Permendagri Nomor 18 tahun 2015 juga tentang hal sama, menjadi perdebatan di berbagai kalangan masyarakat khusunya yang tinggal diperbatasan Kota Pekanbaru dan Kabupaten Kampar sehingga terjadi polemik yang menyebabkan adanya gerakan masyarakat menolak terhadap keputusan permendagri tersebut. Keputusan permendagri tersebut bertentangan dengan peraturan pemerintah sebelumnya yang di anggap sebagai peraturan lanjutan dari undang-undang.

Dalam regulasi Permendagri No. 18 Tahun 2015 telah ditetapkan batas daerah secara pasti antara Kabupaten Kampar dengan Kota Pekanbaru, terkait 3 RW yaitu RW 15 dan RW 16 serta RW 18 Kelurahan Simpang Tiga masuk pada wilayah Kabupaten Kampar. Namun, data base untuk penduduk 3 RW tersebut masih sesuai dengan Daftar Penduduk Potensial Pemilih Pilkada (DP4). Dimana dokumen kependudukan yang dimiliki masih KTP Kota Pekanbaru. Secara administrasi, domain penduduk untuk berpartisipasi dalam pilkada lebih cendrung pada pilkada pekanbaru. Akan tetapi, daulat politik warga 
menjelang pilkada tahap II dilaksanakan sangat di tentukan oleh kepentingan dan afiliasi politik warga masing-masing terhadap pilihan politiknya.

Proses pemutakhiran data pemilih didaerah perbatasan itu menjadi terkendala karena putusan KPUD menggunakan e-KTP, padahal warga di daerah tersebut masih banyak yang menggunakan KTP konvensional. Kondisi itu berdampak terhadap lambatanya penetapan Daftar pemilih sementara (DPS) ke Daftar pemilih tetap (DPT). Potensi permasalahan DPT didaerah perbatasan dikwatirkan akan menjadi konflik pilkada tahap II di Provinsi Riau. Berikut alur penetapan DPT sebagaimana yang dilakukan oleh KPUD.

\section{b. Komitmen Pemerintah Pekanbaru dan Kampar}

Sesuai Permendagri No. 18 Tahun 2015 telah ditetapkan batas daerah secara pasti antara Kabupaten Kampar dengan Kota Pekanbaru terkait 3 RW yaitu RW 15 dan RW 16 serta RW 18 Kelurahan Simpang Tiga Data base untuk penduduk 3 RW tersebut masih sesuai dengan Daftar Penduduk Potensial Pemilih Pilkada (DP4). Dimana dokumen kependudukan yang dimiliki masih KTP Kota Pekanbaru. Untuk itu Perlu kiranya kedua kepala daerah Bupati Kampar dan Walikota Pekanbaru beserta instansi terkait untuk membahas agar tidak terjadi konflik pilkada dikemudian hari. Akan tetapi kondisi ini direspon oleh pemerintah ketika sudah masuk dalam tahapan pilkada pada bulan desember 2016.

Terlihat minimnya komitmen dari kedua kepala daerah baik Pekanbaru maupun Kampar untuk segera menyelesaikan persoalan perbatasan. Sebagaimana mestinya tugas kepala daerah harus mampu menentramkan dan menjaga iklim warga dari berbagai persoalan. Tuntutan masyarakat seyogyanya belum terakomodir, bahkan regulasi tersebut baru disosialisasikan pada awal 2016. Transisi pemerintahan juga menjadi permasalahannya dalam proses penyelesaian sengketa tapal batas, selain itu pertanggung jawaban terhadap pemerintah pusat juga menjadi hal yang imperior, regulasi tersebut dikeluarkan oleh pusat. Perlu kiranya kedua kepala daerah Bupati Kampar dan Walikota Pekanbaru beserta instansi terkait untuk membahas melalui rapat lanjutan, namun hal ini belum menjadi tindak lanjut karena kedua daerah tersebut terjadi pergantian kepala daerah sementara akibat habisnya masa jabatan dari kepala daerah. Belarutnya penyelesaian permasalahan ini menjadi ukuran lemahnya komitmen dari pemerintah daerah dalam penyelesaian sengketa perbatasan.

c. Kepentingan Individu Warga Masyarakat

Keikutsertaan warga dalam memberikan hak suara dalam pemilihan kepala daerah menjadi salah satu indikator dalam kesuksesan pilkada menuju demokrasi lokal yang terkonsolidasi dan berkualitas. Partisipasi politik warga masyarakat adalah kesadaran masyarakat untuk ikut berperan aktif dalam memberikan pilihan politiknya, hal inilah yang menjadi bahagian penting dalam suatu pelaksanaan pilkada, dan secara terus menerus diupayakan oleh penyelenggra demokrasi modern yaitu KPUD tentunya.Dalam penyelenggaran pilkada pekanbaru semua tidak terlepas dari berbagai macam kepentingan dari warga masyarakat ataupun calon (konstestan) itu sendiri. Maka yang menjadi lambatnya pemutakhiran data karena menyangkut kepentingan yang berbeda-beda dari warga masyarakat dan Elit politik tim sukses, dan pasangan calon kepala daerah. Bentuk kepentingan politik warga masyarakat didaerah perbatasan menyangkut kepastian status kependudukan, pelayanan dan pembangunan jangka panjang.

d.Kepentingan KPUD Kota Pekanbaru

Sebagai penyelenggara pemilihan umum (pemilu), atau dalam kontek penelitian ini dalam Pilkada, KPUD Kota Pekanbaru tentunya berkepentingan dalam mewujudkan pilkada yang lancar, sukses dan berhasil. Target KPUD Kota Pekanbaru dalam Indikator keberhasilan pilkada tersebut yaitu

1.Tingginya Partisipasi Pilkada 2017 yaitu 78,5\% (Pilkada 2015: 60\%)

2.Minimnya pelanggaran yang terjadi 
3.Jumlah DPT dan DPS yang sekarang dilakukan dengan Sistem Elektronik KTP dan Surat Keterangan 4.Sosialisasi bersama masyarakat untuk ikut memilih ke TPS

e.Fisibilitas Data Pemilih dengan Partisipasi Politik Masyarakat Kota Pekanbaru

KPUD Kota Pekanbaru mencoba memutuskan dan melakukan verifikasi data pemilih diwilayah perbatasan dengan melakukan pendataan pemilih berdasarkan KTP warga. Alasannya adalah karena secara hukum formal untuk memastikan kependudukan warga sementara adalah dengan adanya data kependudukan melalui perekaman yang dilakukan oleh pemerintah terhadap warganya. Keputusan ini menjadi bentuk KPUD tetap memfasilitasi hak pilih wargadalam politik Setelah proses tersebut dilakukan, fisibilitas perubahan data pemilih pekanbaru. Berikut Rekapitulasi Daftar Pemilih Tetap (DPT) pada Pilkada Tahun 2017 di Kota Pekanbaru dan Kabupaten Kampar.

\begin{tabular}{|c|c|c|c|c|c|c|c|}
\hline \multirow{2}{*}{ NO } & KABUPATEN/ & JUMLAH & JUMLAH & JUMLA & \multicolumn{3}{|c|}{ JUMLAH PEMILIH } \\
\cline { 6 - 8 } & KOTA & KECAMATAN & DESA/KEL & H TPS & L & P & L+P \\
\hline 1 & PEKANBARU & 12 & 58 & 1.796 & $\begin{array}{c}285.3 \\
72\end{array}$ & $\begin{array}{c}286.65 \\
7\end{array}$ & 572.029 \\
\hline & TOTAL & 12 & 58 & 1.796 & $\begin{array}{c}285.3 \\
72\end{array}$ & $\begin{array}{c}286.65 \\
7\end{array}$ & 572.029 \\
\hline
\end{tabular}

Sumber: KPUD Kota Pekanbaru 2016

Hasil verifikasi data pemilih bertolak belakang dengan target partisipasi politik masyarakat pekanbaru yang sudah ditetapkan KPUD. Oleh karena itu fisibilitas pilkada pekanbaru berdasarkan partisipasi masyarakat belum terwujud secara optimal dan signifikan, partisipasi politik masyarakat pekanbaru dalam pilkada serentak 2017 hanya berkisar 49,96 \% yang ikut berpartisapasi. Berikut rekapitulasi perolehan suara dalam pilkada serentak tahap II pilkada Kota Pekanbaru.

\begin{tabular}{|c|c|c|c|}
\hline No Urut & $\begin{array}{c}\text { Nama Pasangan } \\
\text { Calon }\end{array}$ & Jumlah Suara & Persentasi \\
\hline 1 & $\begin{array}{c}\text { Syahril dan Said } \\
\text { Zohrin }\end{array}$ & 22202 & $8,09 \%$ \\
\hline 2 & $\begin{array}{c}\text { Herman Nazar dan } \\
\text { Defi Warman }\end{array}$ & 46606 & $15,74 \%$ \\
\hline 3 & $\begin{array}{c}\text { Firdaus dan Ayat } \\
\text { Cahyadi }\end{array}$ & 94784 & $32,13 \%$ \\
\hline 4 & $\begin{array}{c}\text { Ramli Walid dan } \\
\text { Irvan Herman }\end{array}$ & 59694 & $21,95 \%$ \\
\hline 5 & $\begin{array}{c}\text { Destriyani Bibra } \\
\text { dan Said Usman } \\
\text { Abdullah }\end{array}$ & 62501 & $22,09 \%$ \\
\hline 6 & Suara Tidak Sah & 7748 & $2,64 \%$ \\
\hline & JUMLAH & 293535 & $100 \%$ \\
\hline
\end{tabular}

Sumber: KPUD Kota Pekanbaru 2017

Dari dua tabel di atas dapat ditarik benang merah jika jumlah data pemilih yang sudah di verifikasi menjadi daftar pemilih tetap (572029) dikurangi dengan jumlah suara sah dan tidak sah $(285787+7748=293535)$ bisa dipastikan pemilih yang tidak ikut berpartisipasi adalah 286242. Jika dipersentasikan maka 50,04\% tidak ikut memilih dalam pilkada serentak tahap II Kota Pekanbaru 2017, 
angka ini mencerminkan kemunduran demokrasi di tingkat lokal. Fisibilitas pilkada Kota Pekanbaru belum optimal dang sangat memprihatinkan dikarenkan angka golputlah yang menjadi pemenang.

Pasca pilkada muncullah polemik yang menyebabkan rendahnya partisipasi politik dalam Pilkada serentak ini terkait dengan pemutakhiran data pemilih dan pemetaan pemilih di daerah perbatasan pasca permendagri Nomor 18 Tahun 2015. Permendagri tersebut mengatur tentang Batas Daerah Kabupaten Kampar dengan Kota Pekanbaru, yaitu ditetapkannya batas daerah secara pasti antara Kabupaten Kampar dengan Kota Pekanbaru. Hal ini berimplikasi terhadap terjadinya perubahan status warga 3 RW dalam pelaksanaan Pemilihan Bupati dan wakil Bupati Kampar, Walikota dan Wakil Walikota Kota Pekanbaru tahun 2017. Adapun RW yang dimaksud diantaranya sebagai berikut:

a. Kelurahan Sidomulyo Barat (RW11/RT 1,2,3, 4,6, dan 7). Terdapat 3 TPS, yaitu TPS 42 , 44 (masuk wilayah Pemilihan Kab. Kampar) dan TPS 43 (masuk ke dalam Wilayah pemilihan Kota Pekanbaru)

b. Kelurahan Tuah Karya (RW21/RT 1,2,3 dan 4 serta RW 13/RT 2 dan 3)

c. Kelurahan Simpang Tiga ( RW 15/RT 5,6 dan RW 16). TPS yang bermaslah adalah TPS 59, 60, 61 dan 62.

Secara administrasi masuk wilayah Kabupaten Kampar, tetapi identitas kependudukan (KTP) yang dimiliki warga adalah identitas kependudukan Kota Pekanbaru. RW 18 Kelurahan Simpang Tiga, wilayah masuk Kabupaten Kampar, tetapi KTP Kota Pekanbaru. Analisis temuan pada daerah perbatasan Kecamatan Simpang Tiga, karena sempat terjadi gerakan masyarakat dengan melakukan tuntutan melalui aksi demo terhadap pemerintah untuk tetap menjadi warga pekanbaru. Karena warga sudah sejak lama memiliki KTP pekanbaru bahkan sebagian aset mereka berada di wilayah pekanbaru. Potensi permasalahan di wilayah kecamatan simpang tiga menjadi sangat tinggi, oleh karena itu KPUD Riau, KPUD Kota Pekanbaru dan KPUD Kabupaten Kampar sangat perlu melakukan pemetaan terhadap masalah yang akan terjadi sebagai gambaran buruk dari terbatasnya masyarakat ikut memili atau berpartisipasi ketika pilkada serentak. Preferensi warga perbatasan tersebut untuk tidak ikut memilih sebagai bentuk kekecewaan terhadap kepastian status kependudukannya yang belum ada jalan keluarnya.

Pilkada serentak tahap II kota Pekanbaru menjadi tamparan atau otokritik bagi penyelenggaraan pilkada dan unsur pemerintah daerah yang memiliki kewenangan dalam menjalankan urusan administrasi pemerintahan demi terwujudnya pemerintahan yang kapabel. Salah satu indikator kesuksesan demokrasi adalah partisipasi politik masyarakat, semakin tinggi tingkat partisipasi politik masyarakat maka legitimasi pemerintahan semakin kuat. Oleh karena itu, fisibilitas data pemilih dan sosialisasi pilkada perlu dilakukan secara terpadu demi demokrasi yang terkonsolidasi di ranah lokal.

\section{KESIMPULAN}

Berdasarkan hasil penelitian di atas dapat disimpulkan bahwa fisipilitas pilkada serentak tahap II Kota Pekanbaru tahun 2017 belum berjalan sebagaimana mestinya target KPUD dalam menetapakan hak pilih berdasarkan KTP Elektronik sangat mengabaikan hak pilih warga yang belum dapat KTP eloktronik, sehingga banyak hak pilih warga yang tidak terdaftar karena masih menggunakan KTP Konvensional. Hal ini berdampak terhadap proses pemutakhiran data pemilih yang memakan waktu panjang. Selanjutnya ada beberapa TPS di daerah RW 15.16 dan 18 yang dihilangkan agar tidak terjadi konflik pilkada dikemudian hari. Implikasinya partisipasi masyarkat relatif diluar target $75 \%$ suara karena partisipasi jika dilihat dari suara sah berkisar 58,9\% Kepentingan politik masyarakat terbelah berdasarkan keuntungan dan afiliasi politik terhadap kandidat yang berkompetisi. Selanjutnya kepentingan sosial KPUD adalah terlaksananya penyelenggaraan pilkada sebagaimana yang sudah dijadwalkan serta tercapainya anugrah demokrasi. Upaya KPUD Riau dalam penyelamatan hak pilih warga perbatasan 
dalam bentuk FGD, Koordinasi dan sinergisitas dengan instansi terkait ketika sudah masuh tahapan pilkada sehingga upaya tersebut dinilai belum efektif.

Berdasarkan kesimpulan di atas, maka peneliti merekomendasikan perlu adanya upaya signifikan yang dilakukan oleh KPUD Kota Pekanbaru di tingkatkan secara massif agar partisipasi politik warga tetap terakomodir dalam helat demokrasi lokal. Perubahan terhadap status kependudukan menjadi bahagian penting untuk ditindak lanjuti secara berkelanjutan dan dibahas oleh pemerintah daerah, KPUD dan masyarakat tempatan agar tidak mengabaikan hak politik warga. Sinergistas antara pemerintah, KPUD dan masyarakat untuk membangun budaya demokrasi yang partisipan perlu diupayakan secara berkelanjutan.

\section{DAFTAR PUSTAKA}

[1].J. Moleong, Lexi, 2011. Metode Penelitian Kualitatif Edisi Revisi. Bandung : PT. Remaja Rosdakarya.

[2]. Prihatmoko, J Joko. 2005. Pemilihan Kepala Daerah Langsung, Filosofi, Sistem dan Problem Penerapan di Indonesia. LP3M. Universitas Wahid Hasyim.

[3]. Sarundajang. 2005. Pemilu Kada Langsung Problem dan Prospek. Kata Hasta Pustaka. Jakarta.

[4]. Sugiyono, 2005. Memahami Penelitian Kualitatif. Bandung: CV. Alfabeta.

[5]. Yandra, Alexsander. M.Si, Mei 2013. Jurnal Alboacen Konflik dan Dinamika Pemerintahan: Pergulatan Rakyat Pasca Reformasi. Labor Ilmu Pemerintahan Fisipol Universitas Abdurrab. Volume 1, Nomor 1, ISSN:2338-2538, alboacenjurnal@gmail.com, 20 Mei 2016.

[6]. Yandra, Alexsander. M.Si, Mei 2014. Jurnal Avicenna: Kendala Dalam Implementasi Kebijakan Publik. Universitas Abdurrab. Volume 4, Nomor 1, ISSN:2089-2268, Fax 0761-859839, 20 Mei 2016.

[7]. Yandra, Alexsander. M.Si, Mei 2015. Jurnal Alboacen Membangun Kepedulian Masyarakat Terhadap Politik dan Pemerintahan. Labor Ilmu Pemerintahan Fisipol Universitas Abdurrab. Volume 3, Nomor 1, ISSN:2338-2538, alboacenjurnal@gmail.com, 20 Mei 2016.

[8]. Yandra, Alexsander. M.Si, April 2016. Jurnal Publika: Partisipasi Masyarakat Dalam Perumusan RPJMD Kota Pekanbaru 2012-2017. Laboratorium Administrasi Publik Fisip Universitas Islam Riau. Volume 2, Nomor 1, ISSN:2502-0757, publika.ap@gmail.com, 20 Mei 2016.

[9]. Yandra, Alexsander. M.Si, Juli 2016. Jurnal Politik dan Masalah Pembangunan: E-Goverment denagn Memanfaatan Teknologi Informasi. Sekolah Pascasarjana Ilmu Politik Universitas Nasional. Volume 12, Nomor 1, ISSN:1978-063X, Journal.unas.ac.id, 15 September 2016

[10]. Yandra, Alexsander. M.Si, Juli 2016. Jurnal Dialektika Publik: Pembentukan Daerah Otonomi Baru Problematik dan Tantangannya di Indonesia. LPPM Universitas Putera Batam. Volume 1, Nomor 1, ISSN:2528-3332, dialektikapublikaupb@ puterabatam.ac.id, 15 September 2016 